\title{
Patient, Physician, and Environmental Predictors of Influenza Vaccination During Primary Care Visits
}

\author{
Sujatha Changolkar, BA ${ }^{7}$, Charles A. L. Rareshide, $M S^{7}$, Christopher K. Snider, MPH', \\ and Mitesh S. Patel, MD, MBA, MS $1,2,3,4$
}

'Penn Medicine Nudge Unit, University of Pennsylvania, Philadelphia, PA, USA; ${ }^{2}$ Perelman School of Medicine, University of Pennsylvania, Philadelphia, PA, USA; ${ }^{3}$ Wharton School, University of Pennsylvania, Philadelphia, PA, USA; ${ }^{4}$ Crescenz Veterans Affairs Medical Center, Philadelphia, PA, USA.

J Gen Intern Med 35(2):611-613

DOI: $10.1007 / \mathrm{s} 11606-019-05017-3$

(c) Society for General Internal Medicine (This is a U.S. government work and not under copyright protection in the U.S.; foreign copyright protection may apply) 2019

\section{INTRODUCTION}

The Centers for Disease Control and Prevention recommend that clinicians offer patients the influenza vaccine. ${ }^{1}$ Yet, even among patients who visited their primary care clinician during the influenza season, more than half were not vaccinated. ${ }^{2}$ Data from the electronic health record or other sources could help to identify factors related to these decisions. While patient perceptions of vaccination have been explored, ${ }^{3}$ larger evaluations of factors related to vaccination during primary care visits have not been well-examined. The objective of this study was to evaluate data from a large primary care network to evaluate patient, physician, and environmental predictors of influenza vaccination.

\section{METHODS}

The sample comprised patients who were due for influenza vaccination and had a visit with their primary care physician (PCP) from 30 Penn Medicine primary care practices located in Pennsylvania and New Jersey. We evaluated the patient's first new or return visit during the 2014-2015 and 2015-2016 influenza seasons (September 1 to March 31). Practice sites were excluded if they had less than 100 eligible patient visits for each season. Patients were excluded if they already received the vaccine or had a contraindication.

Similar to prior work, ${ }^{4,5}$ Clarity, an Epic reporting database, was used to obtain data on patients, physicians, clinic visits, and influenza vaccination orders. Data on physician characteristics was obtained from publicly available websites. Weather Underground, a publicly available website, was used to gather weather data. Median household income level was acquired from U.S. Census data.

Received April 3, 2019

Accepted April 8, 2019

Published online May 6, 2019
In the adjusted analysis, a generalized linear model with logit link was fit to the binary outcome of influenza vaccination and included practice site fixed effects as well as patient, physician, and environmental predictor variables.

This study was approved by the University of Pennsylvania institutional review board which granted a waiver of informed consent because the study posed minimal risk and it was infeasible given the retrospective study design. Analyses were conducted in $\mathrm{R}$ (version 3.5.1; R Foundation for Statistical Computing).

\section{RESULTS}

The sample comprised 127,021 patient encounters and 188 PCPs. The overall influenza vaccination rate was $33.9 \%$. Sample characteristics and adjusted predictors of vaccination are displayed in Table 1. Patient predictors with significantly higher odds of vaccination included older age, male sex, white race, and a higher Charlson Comorbidity Index. Vaccination rates were higher at return visits than new patient visits. Physician predictors with significantly higher odds of vaccination included internal medicine specialty, doctor of osteopathy degree, and clinical experience of less than 5 years or greater than 10 years. Significant environmental predictors included time (appointment time, day of week, and month of the year) and weather (average temperature and precipitation).

\section{DISCUSSION}

Influenza vaccination rates in the USA have remained unchanged for nearly a decade with $60 \%$ of Americans not receiving the vaccine each year. ${ }^{6} \mathrm{~A}$ better understanding of the factors related to vaccination could help to inform the design of new, more targeted interventions. In this evaluation of 30 primary care practices over a 2-year period, we found that patient, physician, and environmental factors were significant predicators of influenza vaccination during primary care visits.

Our findings reveal several new insights. First, large differences in vaccination rates existed based on patient race, indicating that interventions should focus on addressing disparities in care. Second, physician training and experience had a significant impact on vaccination rates. Third, as found in 
Table 1 Sample Characteristics and Adjusted Predictors of Influenza Vaccination

\begin{tabular}{|c|c|c|c|c|}
\hline Characteristic & Patient sample, $N(\%)$ & Received vaccination, $N(\%)$ & Odds ratio $(95 \% \mathrm{CI})$ & $P$ value \\
\hline Overall & $127,021(100)$ & $43,001(33.9)$ & - & - \\
\hline \multicolumn{5}{|l|}{ Patient characteristics } \\
\hline Age, years & - & _- & $1.02(1.01-1.02)$ & $<0.001$ \\
\hline \multicolumn{5}{|l|}{ Sex } \\
\hline Male & $55,068(43.4)$ & $18,952(34.4)$ & $1.13(1.10-1.16)$ & $<0.001$ \\
\hline Female & $71,953(56.6)$ & $24,049(33.4)$ & Ref & \\
\hline \multicolumn{5}{|l|}{ Race/ethnicity } \\
\hline Black Non-Hispanic & $30,612(24.1)$ & $10,613(34.7)$ & $0.83(0.80-0.86)$ & $<0.001$ \\
\hline Hispanic & $3519(2.8)$ & $761(21.6)$ & $1.05(0.94-1.16)$ & 0.39 \\
\hline Other & $12,244(9.6)$ & $3505(28.6)$ & $0.91(0.87-0.95)$ & $<0.001$ \\
\hline White Non-Hispanic & $80,646(63.5)$ & $28,122(34.9)$ & Ref & \\
\hline Median household income, per $\$ 10,000$ & - & - & $1.01(1.004-1.02)$ & 0.001 \\
\hline \multicolumn{5}{|l|}{ Insurance } \\
\hline Medicaid & $6621(5.2)$ & $1785(27.0)$ & $1.12(1.04-1.19)$ & 0.001 \\
\hline Medicare & $37,480(29.5)$ & $17,921(47.8)$ & $1.29(1.25-1.35)$ & $<0.001$ \\
\hline Commercial/other & $82,920(65.3)$ & $23,295(28.1)$ & Ref & \\
\hline Charlson Comorbidity Index & - & - & $1.02(1.02-1.03)$ & $<0.001$ \\
\hline \multicolumn{5}{|l|}{ Physician characteristics } \\
\hline \multicolumn{5}{|l|}{ Specialty } \\
\hline Internal medicine & $71,073(56.0)$ & $27,027(38.0)$ & $1.38(1.30-1.47)$ & $<0.001$ \\
\hline Family medicine & $55,948(44.0)$ & $15,974(28.6)$ & Ref & \\
\hline \multicolumn{5}{|l|}{ Degree } \\
\hline DO & $16,828(13.2)$ & $5265(31.3)$ & $1.33(1.26-1.41)$ & $<0.001$ \\
\hline MD & $110,193(86.8)$ & $37,736(34.2)$ & Ref & \\
\hline \multicolumn{5}{|l|}{ Sex } \\
\hline Female & $58,164(45.8)$ & $18,261(31.4)$ & $1.03(0.997-1.06)$ & 0.07 \\
\hline Male & $68,857(54.2)$ & $24,740(35.9)$ & Ref & \\
\hline \multicolumn{5}{|l|}{ Years in practice } \\
\hline$<5$ & $6540(5.1)$ & $2484(26.7)$ & $1.27(1.18-1.36)$ & $<0.001$ \\
\hline $5-10$ & $16,875(13.3)$ & $4500(34.8)$ & Ref & \\
\hline$>10$ & $103,606(81.6)$ & $36,017(38.0)$ & $1.12(1.07-1.17)$ & $<0.001$ \\
\hline \multicolumn{5}{|l|}{ Visit type } \\
\hline New visit & $17,389(13.7)$ & 3754 (21.6) & Ref & \\
\hline Return visit & $109.632(86.3)$ & $39,247(35.8)$ & $1.18(1.13-1.23)$ & $<0.001$ \\
\hline Environmental characteristics & & & & \\
\hline Average temperature, Fahrenheit & - & _- & $0.997(0.995-0.999)$ & 0.003 \\
\hline Precipitation & & & & \\
\hline Yes & $38,630(30.4)$ & $12,450(32.2)$ & $1.05(1.02-1.08)$ & 0.003 \\
\hline No & $88,391(69.6)$ & $30,551(34.6)$ & Ref & \\
\hline Appointment hour & & & & \\
\hline 8 AM & $16,413(12.9)$ & $6227(37.9)$ & Ref & \\
\hline $9 \mathrm{AM}$ & $20,458(16.1)$ & $7688(37.6)$ & $0.94(0.90-0.98)$ & 0.01 \\
\hline $10 \mathrm{AM}$ & $19,744(15.5)$ & $7350(37.2)$ & $0.86(0.82-0.90)$ & $<0.001$ \\
\hline $11 \mathrm{AM}$ & $13,935(11.0)$ & $4742(34.0)$ & $0.73(0.70-0.77)$ & $<0.001$ \\
\hline $12 \mathrm{PM}$ & $4036(3.2)$ & $1284(31.8)$ & $0.66(0.61-0.71)$ & $<0.001$ \\
\hline $1 \mathrm{PM}$ & $13,155(10.4)$ & $4300(32.7)$ & $0.78(0.74-0.82)$ & $<0.001$ \\
\hline $2 \mathrm{PM}$ & $14,989(11.8)$ & $4783(31.9)$ & $0.76(0.72-0.81)$ & $<0.001$ \\
\hline $3 \mathrm{PM}$ & $13,508(10.6)$ & $3796(28.1)$ & $0.65(0.62-0.69)$ & $<0.001$ \\
\hline $4 \mathrm{PM}$ & $7738(6.1)$ & $2068(26.7)$ & $0.59(0.55-0.63)$ & $<0.001$ \\
\hline $5 \mathrm{PM}$ & 3045 (2.4) & $763(25.1)$ & $0.66(0.60-0.72)$ & $<0.001$ \\
\hline Day of week & & & & \\
\hline Mon & $27,916(22.0)$ & $9742(34.9)$ & Ref & \\
\hline Tues & $28,311(22.3)$ & $9896(35.0)$ & $0.99(0.95-1.03)$ & 0.7 \\
\hline Wed & $27,081(21.3)$ & $8860(32.7)$ & $0.89(0.86-0.93)$ & $<0.001$ \\
\hline Thur & $24,071(19.0)$ & $8128(33.8)$ & $0.91(0.88-0.95)$ & $<0.001$ \\
\hline Fri & $19,642(15.5)$ & $6375(32.5)$ & $0.89(0.85-0.93)$ & $<0.001$ \\
\hline Week of month & & & & \\
\hline 1 & $29,768(23.4)$ & $9958(33.5)$ & Ref & \\
\hline 2 & $31,515(24.8)$ & $10,762(34.1)$ & $1.09(1.05-1.13)$ & $<0.001$ \\
\hline 3 & $30,445(24.0)$ & $10,578(34.7)$ & $1.08(1.04-1.13)$ & $<0.001$ \\
\hline 4 & $25.214(19.9)$ & $8242(32.7)$ & $1.06(1.01-1.10)$ & $<0.001$ \\
\hline 5 & $10,079(7.9)$ & $3461(34.3)$ & $1.11(1.05-1.17)$ & $<0.001$ \\
\hline Month of flu season & & & & \\
\hline September & $33,892(26.7)$ & $11,369(33.5)$ & Ref & \\
\hline October & $28,834(22.7)$ & $15,657(54.3)$ & $2.52(2.42-2.63)$ & $<0.001$ \\
\hline November & $17,727(14)$ & $8284(46.7)$ & $1.84(1.73-1.96)$ & $<0.001$ \\
\hline December & $13,568(10.7)$ & $4514(33.3)$ & $1.07(0.99-1.15)$ & 0.08 \\
\hline January & $11,393(9.0)$ & $2090(18.3)$ & $0.49(0.44-0.54)$ & $<0.001$ \\
\hline February & $10,778(8.5)$ & $974(9.0)$ & $0.21(0.19-0.24)$ & $<0.001$ \\
\hline March & $10,829(8.5)$ & $113(1.0)$ & $0.02(0.02-0.03)$ & $<0.001$ \\
\hline Influenza season year & & & & \\
\hline $2014-2015$ & $62,623(49.3)$ & $20,244(32.3)$ & Ref & \\
\hline $2015-2016$ & $64,398(50.7)$ & $22,757(35.3)$ & $1.24(1.21-1.28)$ & $<0.001$ \\
\hline
\end{tabular}

*Patient sample displays column percents among the overall group; received vaccination displays row percents within a characteristic (e.g., $\%$ vaccinated among males) 
our prior work, ${ }^{4}$ appointment time of day was associated with variations in vaccination rates. However, variations were also found to exist at other intervals of time, most notably by month. Interventions might focus on improving vaccination rates between January and March, particularly for more harsh or extended influenza seasons. Fourth, weather was a significant predictor of vaccination and more study is needed to understand how it influences patient perceptions and behaviors.

This study is limited in that it was conducted with a single academic health system. There may be other factors related to vaccination that were not available; however, to our knowledge, this is one of the first studies to evaluate predictors across these multiple levels.

In summary, we identified significant predictors of influenza vaccination at the patient, physician, and environmental levels. Future research should consider these factors when designing interventions to improve influenza vaccination.

Funding Support. This study was supported by the University of Pennsylvania Health System through the Penn Medicine Nudge Unit.

Corresponding Author: Mitesh S. Patel, MD, MBA, MS; Crescenz Veterans Affairs Medical Center, Philadelphia, PA, USA (e-mail: mpatel@pennmedicine.upenn.edu).

\section{Compliance with Ethical Standards:}

This study was approved by the University of Pennsylvania institutional review board which granted a waiver of informed consent because the study posed minimal risk and it was infeasible given the retrospective study design.
Conflict of Interest: Dr. Patel is supported by career development awards from the Department of Veterans Affairs HSR\&D and the Doris Duke Charitable Foundation. Dr. Patel is a founder of Catalyst Health, a technology and behavior change consulting firm. Dr. Patel also has received research funding from Deloitte, which is not related to the work described in this manuscript. No other disclosures were reported.

Role of the Funder/Sponsor: The funder had no role in the design and conduct of the study; collection, management, analysis, and interpretation of the data; preparation, review, or approval of the manuscript; and decision to submit the manuscript for publication.

Access to Data and Data Analysis: Ms. Changolkar and Dr. Patel had full access to all the data in the study and take responsibility for the integrity of the data and the accuracy of the data analysis.

\section{REFERENCES}

1. Grohskopf LA, Sokolow LZ, Broder KR, et al. Prevention and control of seasonal influenza with vaccines: recommendations of the Advisory Committee on Immunization Practices - United States, 2017-18 Influenza Season. MMWR Recomm Rep. 2017;66(2):1-20.

2. Lu PJ, O'Halloran A, Ding H, Srivastav A, Williams Ww. Uptake of influenza vaccination and missed opportunities among adults with highrisk conditions, United States, 2013. Am J Med. 2016;129(6):636 e631636 e611.

3. Larson HJ, Jarrett C, Eckersberger E, Smith DM, Paterson P Understanding vaccine hesitancy around vaccines and vaccination from a global perspective: a systematic review of published literature, 20072012. Vaccine. 2014;32(19):2150-2159.

4. Kim RH, Day SC, Small DS, Snider CK, Rareshide CL, Patel MS. Variations in influenza vaccination by clinic appointment time and an active choice intervention in the electronic health record to increase influenza vaccination. JAMA Netw Open. 2018;1(5):e181770.

5. Kannan S, Asch DA, Kurtzman GW, Honeywell S Jr., Day SC, Patel MS. Patient and physician predictors of hyperlipidemia screening and statin prescription. Am J Manag Care. 2018;24(8):e241-e248.

6. Centers for Disease Control and Prevention. Influenza Vaccination Coverage. https://www.cdc.gov/flu/fluvaxview/index.htm. 2018. Accessed March 15, 2019.

Publisher's Note Springer Nature remains neutral with regard to jurisdictional claims in published maps and institutional affiliations. 